\title{
Feeding Intolerance, AE
}

National Cancer Institute

\section{Source}

National Cancer Institute. Feeding Intolerance, AE. NCI Thesaurus. Code C154944.

An adverse event in a newborn characterized by inability to achieve a full feeding volume. 